\title{
Canada has long way to go on virtual care
}

\author{
Cite as: CMAJ 2020 March 2;192:E227-8. doi: 10.1503/cmaj.1095851
}

Posted on cmajnews.com on February 12, 2020

anada is a long way from having the virtual care that is available in other countries, according to a national task force examining why most Canadians still can't book medical appointments online, text with their doctors, or easily access their electronic medical records.

In a recent report, the task force makes 19 recommendations for scaling up virtual care. But at the current rate of progress, "it will take Canada years to achieve the level of virtual care that we think patients deserve," said task force co-chair Dr. Douglas Hedden of the Royal College of Physicians and Surgeons of Canada at a panel discussion in Ottawa. "Unless appropriate actions are taken, virtual care will remain fragmented and not delivered in an equitable fashion."

Led by the Canadian Medical Association (CMA), the College of Family Physicians of Canada, and the Royal College, the task force is calling for a pan-Canadian framework to address gaps in standards, licensure, quality of care, payment and medical education.

"This isn't about fancy technology," Hedden noted. Most Canadians already have mobile phones and the Internet, and many patients say they would use telemedicine if it was available.

\section{Major gaps remain}

Although most doctors and health facilities in Canada now use some form of digital record keeping, surveys show fewer than one in 10 family physicians allow patients to book appointments electronically, less than a quarter make themselves available by email, and just $4 \%$ provide video visits. According to the 2019 CMA Physician Workforce Survey, half of all family doctors and other specialists offer no interactive electronic services to patients.

For patients, this can mean long waits and expensive travel to address issues that could have been resolved in a few minutes by phone, text, email or video chat. Julie Drury of the Canadian Foundation for Healthcare Improvement shared the story of a friend who drives six hours from Ontario to Manitoba to see her specialist for 15-minute checkups. In such cases, virtual care would be a "game changer," she said.

Accessing health information can be time-consuming and costly, too. Even where there are patient portals, health officials set limits on when and how much information is released. "That's not ownership. When I own something, I can access it with immediacy, I get to decide who sees it, and I get to decide how it's used," Drury said.

However, systems south of the border are showing the possibilities of virtual care. In the Kaiser Permanente System in the United States, about half of patient interactions with health teams were virtual in 2016, including some 30 million secure messages, 6.2 million telephone appointments, and almost 100000 video visits.

\section{Bureaucratic barriers}

Many of the barriers in Canada, it seems, are bureaucratic. There are no national standards for patient access to health

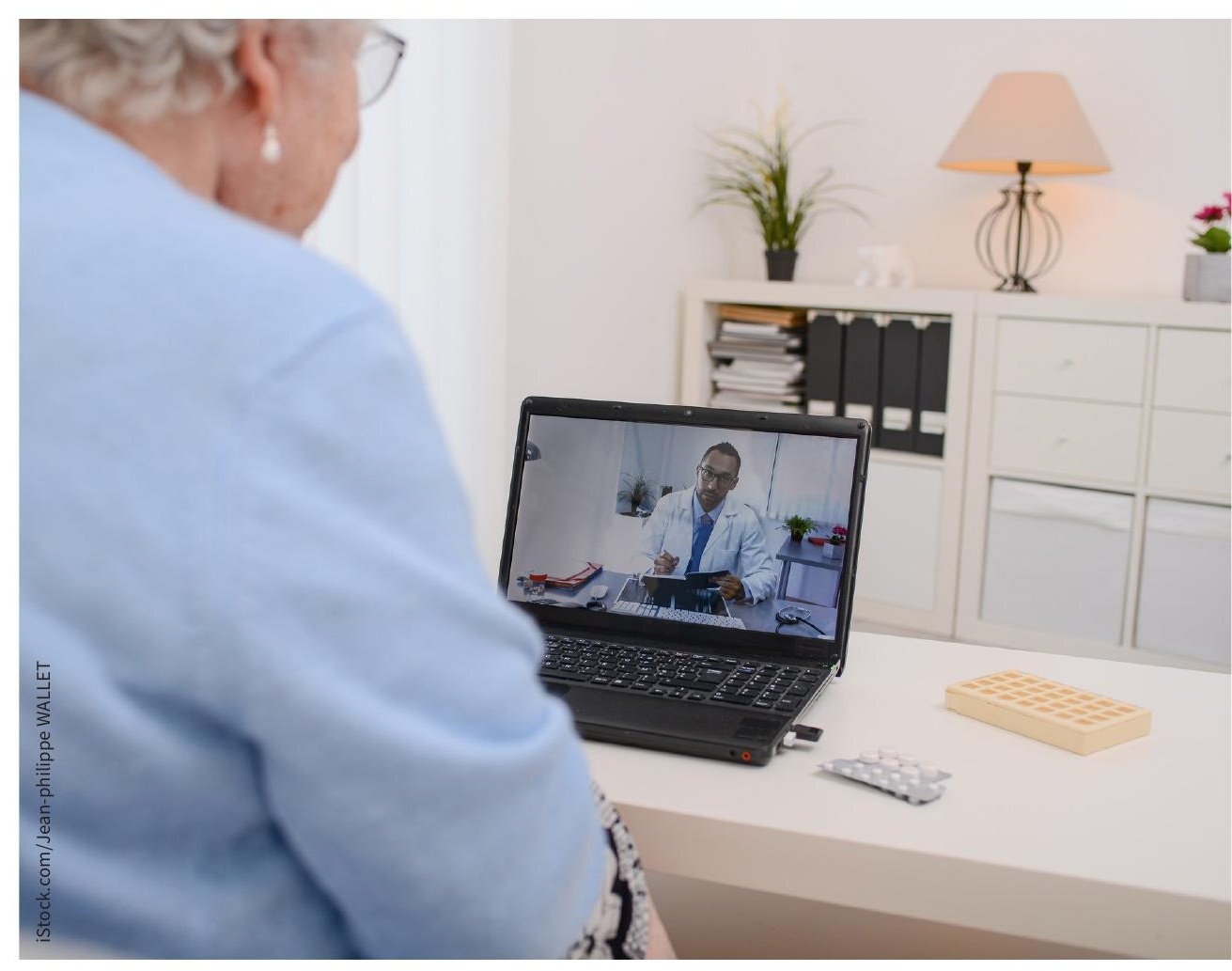

A national report urges action to scale up video consults and other virtual care. 
information, or for the safety and quality of virtual care. Electronic medical systems are often designed locally or regionally, and don't talk to one another. Medical licensing rules pose barriers to physicians working across provincial borders, even virtually. And provincial public health plans may not compensate doctors for virtual care services.

Some of the gaps identified in the report were surprising, said task force cochair Dr. Gigi Osler, past president of CMA. "For example, there not being any sort of framework to ensure the safety and quality of virtual health care; you would have thought that would have been in place before virtual care came to Canada."

Meanwhile, private virtual care has proliferated in the absence of publicly funded options. "The technology is here, and it is being used in mostly the private system," said Osler. "If we don't think of innovative ways to bring this technology to the public health care system, we're only going to see the gaps increase between those who can afford it and those who cannot."

Among their key recommendations, the task force calls for:

- National standards for patient health information access;

- A framework to regulate the safety and quality of virtual care;

- The development of new fee schedules for in-person and virtual care that are revenue neutral;

- The incorporation of virtual care in medical schools and continuing education;

- And increased support to regulatory bodies to simplify physician registration and licensure processes.

However, the task force stops short of calling for national licensure for doctors, something supported by more than nine in 10 physicians surveyed by CMA. According to Osler, "You need to have some form of national license that allows care to be provided across boundaries if we really want to experience the full potential of virtual care."
According to Dr. Linda Inkpen, president of the Federation of Medical Regulatory Authorities of Canada, the hands of regulators are tied by Canada's constitution and the fact that medical regulation comes under the authority of the provinces. Similar issues have come up in other federated countries like Australia, where the federal, state and territorial governments ultimately agreed to establish a single registration and accreditation system for all health professionals in the country.

The Federation of Medical Regulatory Authorities of Canada is working on initiatives to support virtual care, including the possibility of allowing physicians to use their license to provide telemedicine in any province or territory.

Osler said the task force avoided prescriptive recommendations, however, "to be open and collaborative, to really set the stage for how we can work together to bring these recommendations to life."

Lauren Vogel, CMAJ 